\title{
A four-year community hospital experience regarding procedures for the replantation and revascularization of fingers
}

\author{
Kaan Gürbüz, MD ${ }^{1,2}$, Yalçın Yontar, MD $^{3,4}$ (D) \\ ${ }^{1}$ Department of Orthopedics and Traumatology, Kayseri Training and Research Hospital, Kayseri, Turkey \\ 2Department of Orthopedics and Traumatology, Kayseri City Training and Research Hospital, Kayseri, Turkey \\ ${ }^{3}$ Department of Plastic Reconstructive and Aesthetic Surgery, Kayseri Training and Research Hospital, Kayseri, Turkey \\ ${ }^{4}$ Department of Plastic Reconstructive and Aesthetic Surgery, Acıbadem Hospital, Kayseri, Turkey
}

\begin{abstract}
Although microsurgery has evolved dramatically over the past decades due to numerous advances in techniques and instrumentation, salvage of an amputated limb or digit, which requires extensive experience, is one of the most complicated procedures a microsurgeon performs. However, careful patient selection, meticulous preoperative management, and continuous postoperative care are critical to ensure optimal postoperative outcomes, as is microsurgical experience. Fortunately, this challenging procedure is currently performed widely in both academic and community practice settings due to increased access to microsurgery training and education opportunities, to restore not only circulation, but also function, sensation and cosmetic appearance. ${ }^{[1-4]}$
\end{abstract}

Received: December 23, 2020

Accepted: March 18, 2021

Published online: June 11, 2021

Correspondence: Kaan Gürbüz, MD. Kayseri Şehir Eğitim ve Araştırma Hastanesi Ortopedi ve Travmatoloji Kliniği,

38039 Kocasinan Kayseri, Türkiye.

E-mail: drkagangurbuz@gmail.com

Doi: 10.52312/jdrs.2021.32

Citation: Gürbüz K, Yontar Y. A four-year community hospital experience regarding procedures for the replantation and revascularization of fingers. Jt Dis Relat Surg 2021;32(2):383-390.

Presented at the International Occupational Accidents, Hand Injuries and Amputations Congress, April 26-27, 2019, Istanbul, Turkey.

(O2021 All right reserved by the Turkish Joint Diseases Foundation

This is an open access article under the terms of the Creative Commons Attribution-NonCommercial License, which permits use, distribution and reproduction in any medium, provided the original work is properly cited and is not used for commercial purposes (http://creativecommons.org/licenses/by-nc/4.0/).

\section{ABSTRACT}

Objectives: This study aims to evaluate the clinical results and experiences in a community hospital regarding procedures for the replantation and revascularization of fingers.

Patients and methods: Between June 2015 and December 2019, a total of 58 patients (51 males, 7 females; mean age: $33.4 \pm 6.3$ years; range, 23 to 46 years) who were followed after total and/or subtotal amputation and replantation were retrospectively analyzed. The patients were evaluated at nine months in terms of cold intolerance, static two-point discrimination, and functional results using the range of motion (ROM) and Quick Disabilities of the Arm, Shoulder and Hand (QuickDASH) questionnaire.

Results: The majority of the patients presented with work-related injuries (70\%), most commonly by the mechanism of guillotine $(64 \%)$, and to the dominant hand $(76 \%)$ and the third finger $(36 \%)$ most frequently. The overall success rate of digit salvage was $72.9 \% \quad(n=51)$. Of 19 digits with unsuccessful surgical outcomes, seven were from total and 12 were from subtotal amputations. In the long-term, cold intolerance was observed in 14 patients $(24.1 \%)$ according to the cold intolerance severity scale. The mean static twopoint discrimination value was $6.0 \pm 0.7 \mathrm{~mm}$ and the mean QuickDASH score was $22.3 \pm 5.0$. The mean ROM measured at nine months after surgery in the metacarpophalangeal and interphalangeal joints of the third and fourth digits was significantly lower than that in the others $(\mathrm{p}<0.05)$.

Conclusion: The predictors of survival of a replanted digit indicated in this study can be used as a guide and decision-making aid for any attempts for replantation.

Keywords: Community hospital, digit, predictors of survival, replantation.

In the literature, there are many published series describing the factors influencing the outcomes of salvage procedures. In the current study, we aimed to present the demographic and clinical characteristics, predictors of survival, and surgical outcomes in a 
community hospital setting regarding procedures for the replantation and revascularization of fingers.

\section{PATIENTS AND METHODS}

This single-center, retrospective study was conducted at Kayseri Training and Research Hospital and Kayseri City Training and Research Hospital, Departments of Orthopedics \& Traumatology and Plastic Reconstructive \& Aesthetic Surgery between June 2015 and December 2019. A total of 37 subtotally amputated digits were revascularized and 38 totally amputated digits were replanted in 63 adult patients. Of the patients, 35 underwent subtotal amputation of a single digit, 16 total amputation of a single digit, and 11 total amputation of two digits. One patient presented with subtotal amputation of the thumb and index digits (Figure 1). Five patients with a totally amputated single digit were excluded from the study due to missing data, lost to follow-up, a postoperative period of less than six months, or not consenting for participation in the study. Finally, the study included a total of 58 patients (51 males, 7 females; mean age: $33.4 \pm 6.3$ years; range, 23 to 46 years) with 70 amputations, of which 37 were subtotal and 33 were total. The Cold Intolerance Severity Scale (CISS), a static two-point discrimination test, and the 11-item Quick Disabilities of the Arm, Shoulder and Hand (QuickDASH) questionnaire were used. The range of motion (ROM) of the phalangeal joints was measured in all patients at nine months.

A written informed consent was obtained from each patient. The study protocol was approved by the Acıbadem Mehmet Ali Aydinlar University Ethics Committee (No: 2019-11/30). The study was conducted in accordance with the principles of the Declaration of Helsinki.

\section{Operative procedure and postoperative care}

All operations were performed under general anesthesia in 12 patients and under peripheral block in 46. The osteosynthesis was performed by a single application of Kirschner wires in 14 digits, miniplates and screws in 28 , external fixators in 4 , and a mixture of these approaches in 12. Debridement of the amputated part was performed via $4.5 \times$ loupe magnification, and the recipient side was prepared for anastomosis under microscope (12.5x) in all cases. The anastomosis and all nerve reconstructions were performed under microscope with 12.5 to $25 \times$ magnification. Microsurgical anastomosis was achieved using 9 to $10 / 0$ nylon for both arteries, veins, and nerves. In 17 cases involving 24 digits, vein grafts were used. In all cases, nerve end-to-end
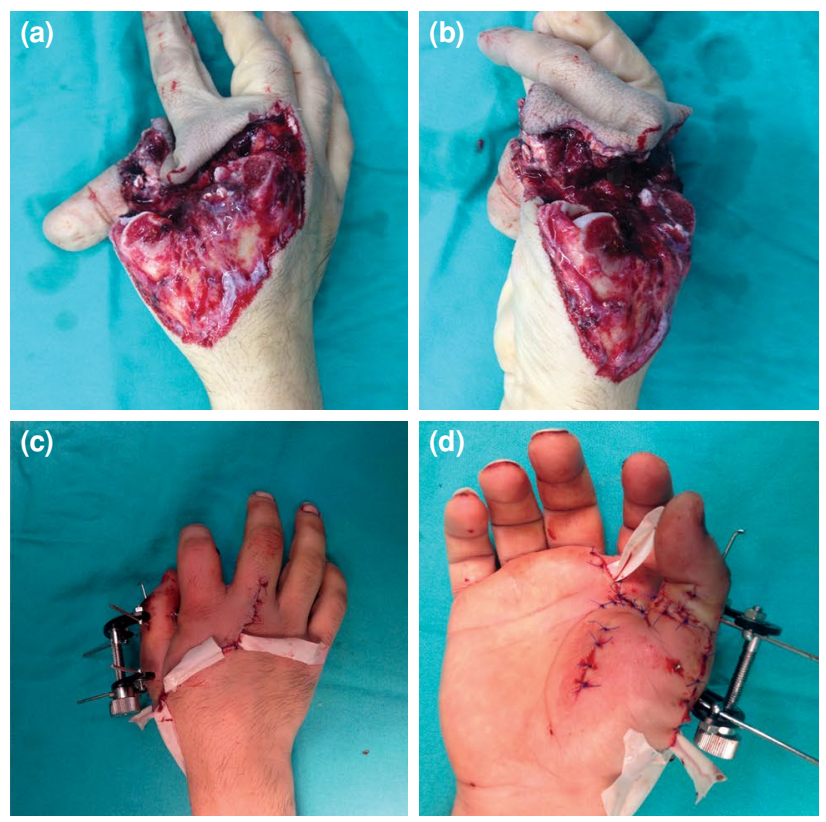

(e)
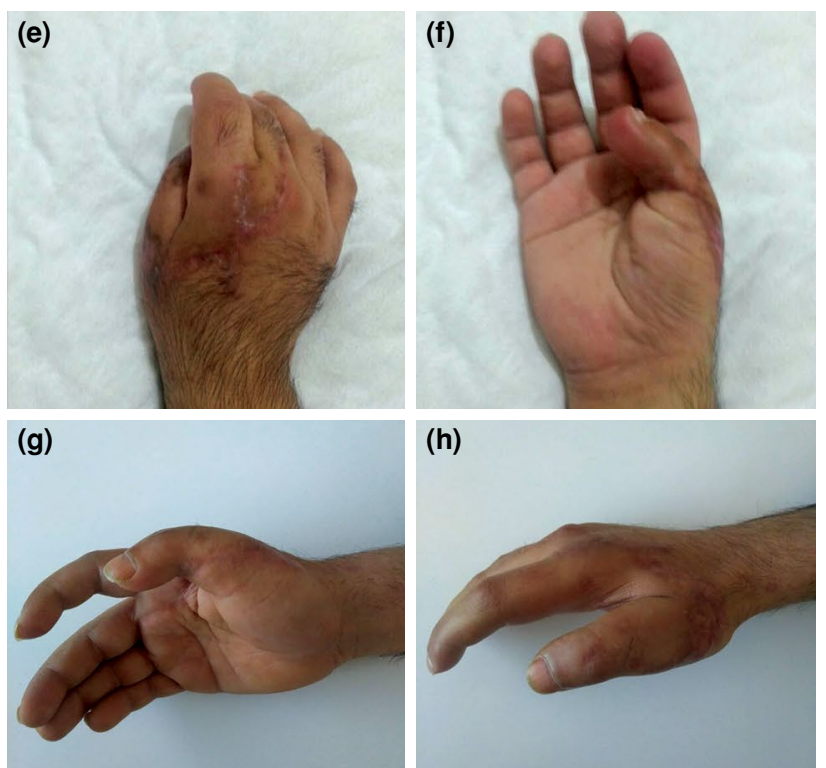

(h)
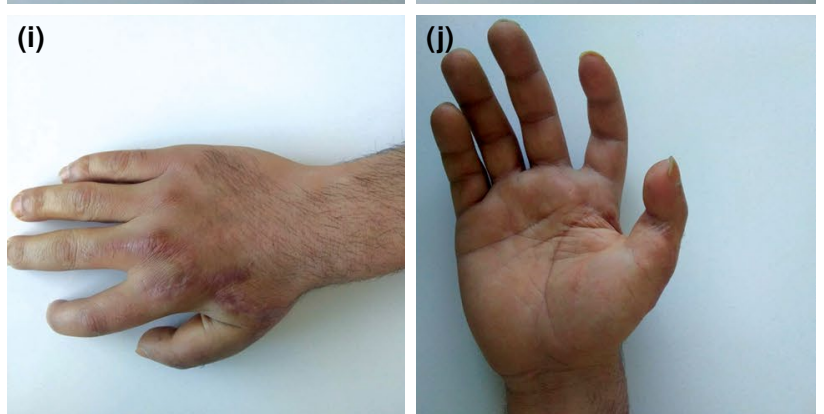

FIGURE 1. From preoperative to late postoperative consecutive views of subtotal amputation of the right thumb and index finger in a 26-year-old male patient due to machinery/tool in the workplace. (a, b) Preoperative views, (c, d) Views just after the replantation operation, (e, f) Early period of the physical therapy and rehabilitation around day $21,(\mathbf{g}-\mathbf{j})$ Late postoperative view of the patient. 
anastomosis was performed, whenever possible. In only two cases involving three digits' replantation with the mechanism of avulsion, only one side of the digital nerves was repaired. Postoperatively, standard microvascular precautions were taken and analgesic, antiaggregant, and prophylactic antibiotic therapy were applied in all patients.

For analgesics, in all cases supra- or infraclavicular peripheral nerve catheterization was performed, and 75 to $100 \mathrm{mg}$ bupivacaine hydrochloride was administered as t.i.d. for at least two days. A total of $4,000 \mathrm{U}$ anti-Xa/0.4 mL was used b.i.d. subcutaneously with a combination of dextran $(500 \mathrm{~mL} / 24 \mathrm{~h})$ and acetylsalicylic acid (10 grains b.i.d.) for at least three days after finger replantation. In addition, prophylactic antibiotic therapy was initiated according to etiology of the amputation, contamination type and level of the amputated and recipient part, properties of the amputation occurred area, nosocomial flora properties, and the surgical site antibiogram by the infectious disease and clinical microbiology specialist.

In digits with poor venous drainage and unresponsive to nailbed bleeding $(n=17)$, medicinal leech therapy was applied by a certified surgeon via the protocol established by the Republic of Turkey, Ministry of Health. The medicinal leeches were provided by the Traditional and Complementary Medicine Department of the hospital from a Hirudo ${ }^{\text {TM }}$ Medical Leech Farm, which has CITES (Convention on International Trade in Endangered Species of Wild Fauna and Flora) and Republic of Turkey, Ministry of Health certificates. Following the leech therapy, none of the patients required blood transfusion.

Surgical success representing the survival of the replanted amputated digit was defined as the full viability of the digit based on its color, temperature, capillary refill time, and pulse oximetry reading at the time of patient discharge and lack of a secondary operation due to circulatory complications, such as stump revision or debridement of necrotic tissue. ${ }^{[5,6]}$ The patients without complications were discharged with a regimen of $300 \mathrm{mg}$ of oral acetylsalicylic acid for the subsequent four weeks, oral antibiotics, and analgesics. Physiotherapy was started on average on Day 21 postoperatively and consisted of early protective active motion, continuous passive motion, splinting, and sensory stimulation.

\section{Statistical analysis}

Statistical analysis was performed using the IBM SPSS for Windows version 22.0 software (IBM Corp., Armonk, NY, USA). Normality assumption was checked using the Shapiro-Wilk test. Descriptive data were expressed in mean \pm standard deviation (SD), median (min-max) or number and frequency, where applicable. In the statistical evaluation of the data, the independent t-test was used for determination of the mean/median differences. The Mann-Whitney $\mathrm{U}$ test was used for those who did not fit the normal distribution. The chi-square test was used to compare the categorical variables. The exact chi-square test was used in the boxes in the software, as there were fewer than five values. The post-hoc analysis was carried out by the Tukey's test. A $p$ value of $<0.05$ was considered statistically significant.

\section{RESULTS}

The mean hospitalization length was $3.2 \pm 0.8$ (range, 2 to 6) days, while the mean follow-up was $34.5 \pm 6.4$ (range, 28 to 44 ) months. The most common cause was work-related injuries $(n=41,70.7 \%)$, followed by home- $(\mathrm{n}=12,20.7 \%)$ and motor vehicle-related injuries $(\mathrm{n}=5,8.6 \%)$. In 23 cases involving amputations, the amputated digits were transported to the hospital in appropriate conditions. Forty-two $(72.4 \%)$ patients were smokers; however, none of the patients had a chronic illness affecting the peripheral circulation.

The mechanism of injury was guillotine in $37(63.8 \%)$ patients, crush in $17(29.3 \%)$, and avulsion in four $(6.9 \%)$. The levels of amputations according to the flexor zones from the $2^{\text {nd }}$ to $5^{\text {th }}$ digits respectively were zone I in seven digits (10\%), zone II in 58 (82\%), and zone III in five (7\%) (Table I).

The injury occurred in the dominant hand in $44(75.8 \%)$ patients and, in patients with total or subtotal amputation of two digits $(\mathrm{n}=12,20.7 \%)$, the injury was unilateral. The $3^{\text {rd }}$ digit $(n=25$ digits, $35.7 \%$ ) was the most frequently affected, followed by the $2^{\text {nd }}(\mathrm{n}=19$ digits, $27.1 \%), 4^{\text {th }}(\mathrm{n}=13$ digits, $18.6 \%), 1^{\text {st }}$ $(\mathrm{n}=7$ digits, $10 \%)$, and $5^{\text {th }}(\mathrm{n}=6$ digits, $8.6 \%)$.

\section{TABLE I}

Digit amputation levels according to the Tamai classification

Level Description of the amputation level

I Distal to $m$. flexor digitorum profundus insertion

II Distal interphalangeal joint to $m$. flexor digitorum profundus insertion

III Middle phalanx distal to $m$. flexor digitorum superficialis insertion

IV Proximal phalanx to middle phalanx $m$. flexor digitorum superficialis insertion

$\mathrm{V} \quad$ Metacarpophalangeal joint and proxima 


\begin{tabular}{|c|c|c|c|c|c|c|}
\hline \multirow[b]{3}{*}{ Variables } & \multicolumn{4}{|c|}{$\begin{array}{l}\text { TABLE II } \\
\text { and variable }\end{array}$} & \multirow[b]{3}{*}{ Total } & \multirow[b]{3}{*}{$p$} \\
\hline & \multicolumn{2}{|c|}{ Digits that survived } & \multicolumn{2}{|c|}{ Digits that failed } & & \\
\hline & $n$ & $\%$ & $n$ & $\%$ & & \\
\hline Age (year) & & & & & & 0.57 \\
\hline$<35$ & 37 & 72.54 & 2 & 10.52 & 39 & \\
\hline $35-59$ & 14 & 27.45 & 17 & 89.47 & 31 & \\
\hline$\geq 60$ & - & - & - & - & - & \\
\hline Total & & & & & 70 & \\
\hline Sex & & & & & & 0.342 \\
\hline Male & 47 & 92.25 & 16 & 84.21 & 63 & \\
\hline Female & 4 & 7.84 & 3 & 15.78 & 7 & \\
\hline Total & & & & & 70 & \\
\hline Dominant hand & & & & & & 0.067 \\
\hline Yes & 38 & 74.5 & 12 & 63.15 & 50 & \\
\hline No & 13 & 25.49 & 7 & 36.84 & 20 & \\
\hline Total & & & & & 70 & \\
\hline Digit & & & & & & 0.0762 \\
\hline Thumb & 7 & 13.72 & - & - & 7 & \\
\hline Index & 18 & 35.29 & 1 & 5.26 & 19 & \\
\hline Middle & 17 & 33.33 & 8 & 42.1 & 25 & \\
\hline Ring & 7 & 13.72 & 6 & 31.57 & 13 & \\
\hline Little & 2 & 3.92 & 4 & 21.05 & 6 & \\
\hline Total & & & & & 70 & \\
\hline Tamai level & & & & & & 0.38 \\
\hline I & - & - & - & - & - & \\
\hline II & 5 & 9.8 & 2 & 10.52 & 7 & \\
\hline III & 17 & 33.33 & 7 & 36.84 & 24 & \\
\hline IV & 25 & 49.01 & 9 & 47.36 & 34 & \\
\hline V & 4 & 7.84 & 1 & 5.26 & 5 & \\
\hline Total & & & & & 70 & \\
\hline Time from injury to surgery & & & & & & 0.572 \\
\hline$<6 \mathrm{~h}$ & 40 & 78.43 & 6 & 31.57 & 46 & \\
\hline $6-10 \mathrm{~h}$ & 11 & 21.56 & 13 & 68.42 & 24 & \\
\hline$>10 \mathrm{~h}$ & - & - & & & - & \\
\hline Total & & & & & 70 & \\
\hline Mechanism of injury & & & & & & 0.754 \\
\hline Guillotine & 26 & 50.98 & 3 & 15.78 & 29 & \\
\hline Crush & 19 & 37.25 & 10 & 52.63 & 29 & \\
\hline Avulsion & 6 & 11.76 & 6 & 31.57 & 12 & \\
\hline Total & & & & & 70 & \\
\hline Tobacco use & & & & & & * \\
\hline Yes & 41 & 80.39 & 12 & 63.15 & 53 & \\
\hline No & 10 & 19.6 & 7 & 36.84 & 17 & \\
\hline Total & & & & & 70 & \\
\hline Artery anastomosis & & & & & & \\
\hline 1 artery & 14 & 27.45 & 11 & 57.89 & 25 & \\
\hline 2 arteries & 37 & 72.54 & 8 & 42.1 & 45 & \\
\hline Total & & & & & 70 & \\
\hline Vein anastomosis & & & & & & * \\
\hline 0 or 1 vein & 12 & 23.52 & 12 & 63.15 & 24 & \\
\hline Multiple veins & 39 & 76.47 & 7 & 36.84 & 46 & \\
\hline Total & & & & & 70 & \\
\hline Vein grafts & & & & & & * \\
\hline Yes & 17 & 27.45 & 7 & 36.84 & 24 & \\
\hline No & 34 & 66.66 & 12 & 63.15 & 46 & \\
\hline Total & & & & & 70 & \\
\hline
\end{tabular}



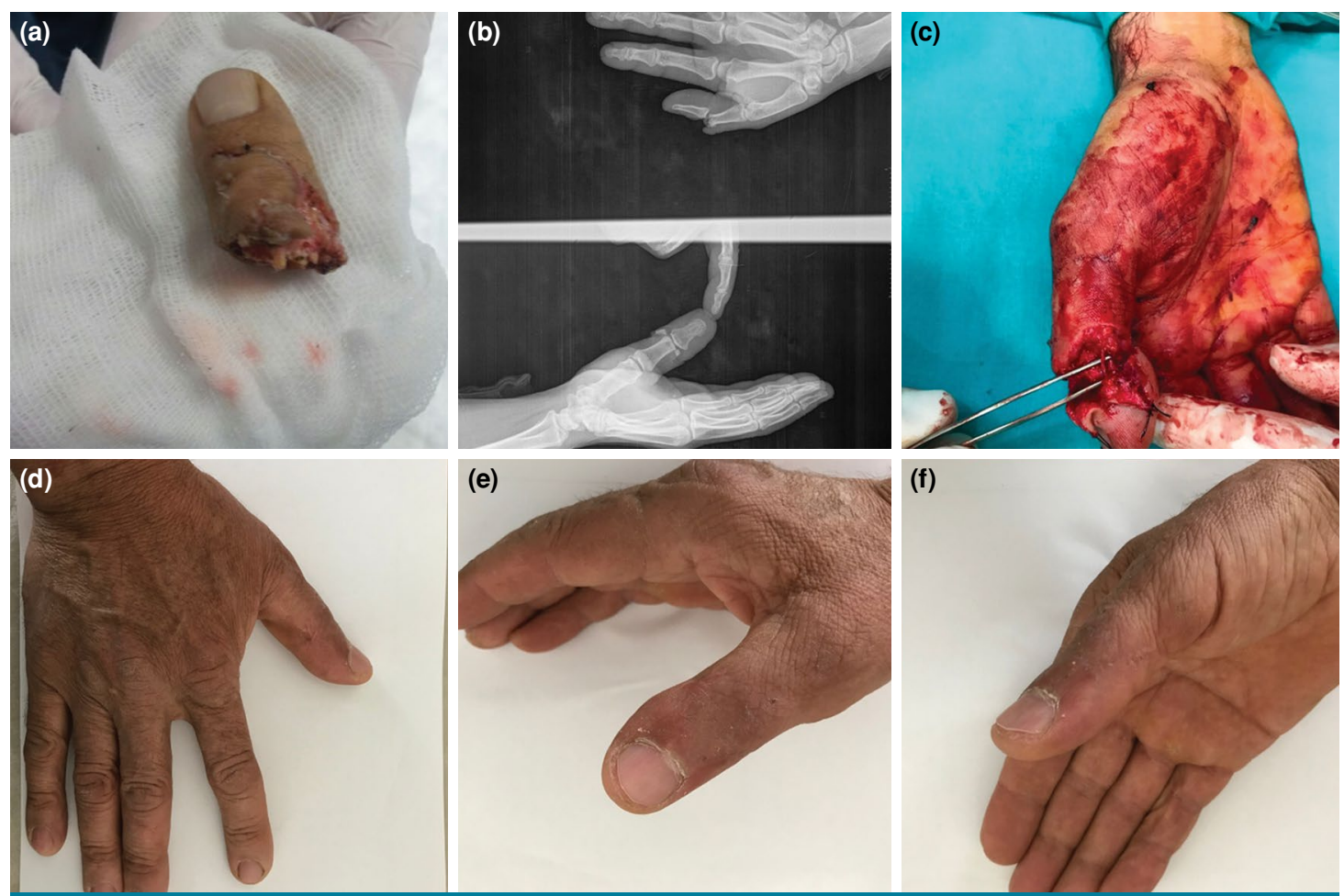

(f)

FIGURE 2. From preoperative to late postoperative consecutive views of total amputation of the right thumb in a 34-year-old male patient with a crush injury. $(\mathbf{a}, \mathbf{b})$ Preoperative views c: Intraoperative view just after the anastomosis of the one side of the digital artery of the thumb. (d-f) Late postoperative view of the thumb.
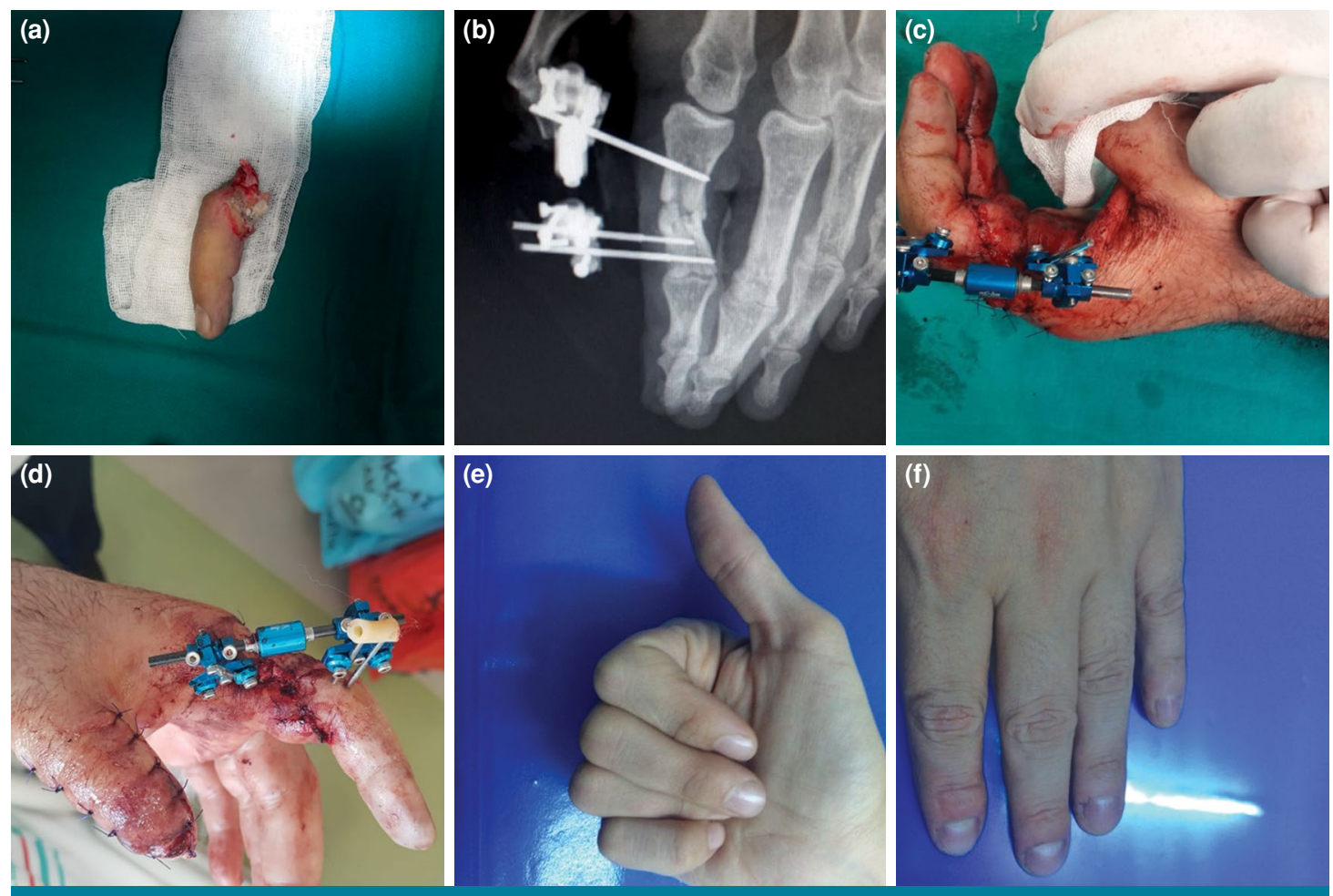

FIGURE 3. From preoperative to late postoperative consecutive views of the total amputation of the left index finger in a 24-year-old male patient, (a) The amputated index finger, b: Postoperative X-ray of the replanted index finger. $(\mathbf{c}, \mathbf{d})$ Early postoperative clinical views of the finger. $(\mathbf{e}, \mathbf{f})$ Late postoperative view of the index finger. 
The mean duration of salvage surgery was $5.6 \pm 0.8$ (range, 3 to 8 ) h, and the surgery was performed over a 6-h operative session during which 17 digits were replanted or revascularized, with a break lasting approximately $20 \mathrm{~min}$. The overall survival rate was $72.9 \%$ ( $\mathrm{n}=51$ digits).

Of the 19 digits with unsuccessful surgical outcomes, seven involved total and 12 involved subtotal amputations. Of these digits, re-anastomosis was performed in five due to failure of arterial anastomosis, but it failed to restore blood flow to the amputated digit.

In the late postoperative period, 22 digits (43.1\%) underwent tenolysis, five $(9.8 \%)$ underwent neuroma excision, and $12(23.5 \%)$ underwent a combination of the two procedures. Cold intolerance was observed in 19 digits of 14 patients (37.3\%) according to the CISS. The mean static two-point discrimination value was $6.0 \pm 0.7$ (range, 5.2 to 8.4 ) $\mathrm{mm}$ and the mean QuickDASH score was $22.3 \pm 5.0$ (range, 16 to 32 ).

The mean ROM values measured at nine months after surgery of the metacarpophalangeal and interphalangeal joints of the $3^{\text {rd }}$ and $4^{\text {th }}$ digits were significantly lower than that of the $2^{\text {nd }}$ digit $(\mathrm{p}<0.05)$. Furthermore, this value for the $3^{\text {rd }}$ digit was lower than that for the $4^{\text {th }}$ digit and higher than that for the $5^{\text {th }}$, although there was no statistically significant difference $(\mathrm{p}>0.05)$.

According to the statistical analysis, sex, increased time to perform the surgery $(>6 \mathrm{~h})$, and whether the amputation was subtotal or total had no significant impact on digit survival ( $>00.05$ ) (Table II). However, variables, including age older than 35 years, smoking, injury to digits of the dominant hand, crush and/or avulsion injury, flexor zone I or Tamai zone II injury, inappropriate preservation of the amputated digit, and injury to the $5^{\text {th }}$ digit adversely impacted the digit survival $(p<0.05)$. Illustrative cases are shown in Figures 1-3.

\section{DISCUSSION}

In the present study, we found that sex, increased time to perform the surgery (over $6 \mathrm{~h}$ ), and whether the amputation was subtotal or total had no effect on digit survival. However, age older than 35 years, tobacco use, crush or crush/avulsion injury, zone I injury, inappropriate preservation of the amputated digit, and injury to the dominant hand's digits or the $5^{\text {th }}$ digit were found to be negative predictors. ${ }^{[7]}$

To date, numerous attempts have been made to improve the surgical outcomes following digit amputations, resulting in physical trauma in individuals, as well as emotional and social traumas. ${ }^{[8,9]}$ In the literature, several reports of replantation/revascularization procedures of the fingers have variable survival rates, which can be attributed to the differences in the study populations such as in sociodemographic factors, clinicopathological characteristics, and surgical selection criteria applied, the experience and equipment of the microsurgical team, etc. In the present study, we reviewed 70 minor replantation/ revascularization procedures in 58 cases and found a $72.9 \%$ survival rate, which is acceptable based on the series reported in the Turkish (50 to $85 \%)^{[3,8,10-14]}$ and English literature (48 to $97 \%$ ). ${ }^{[15-19]}$

Predicting the success of digit salvage remains a challenging task, and with the increased number of published series having conflicting results, interpreting the predictors of digit survival has become difficult. ${ }^{[16]}$ In a recent meta-analysis of 32 studies representing more than 6,000 replanted/ revascularized digits, the number of venous and arterial anastomoses and the mechanism of injury were the main predictors of digit survival. ${ }^{[19]}$ However, no significant association was found between survival and different variables, including age, sex, zone of injury, digit number, tobacco use, ischemia time, method of preservation, and use of vein grafts. On the other hand, in this study, age older than 35 years, tobacco use, crush or crush/avulsion injury, zone I injury, inappropriate preservation of the amputated digit, and injury to the dominant hand's digits or the $5^{\text {th }}$ digit were found to be negative predictors, which is a valuable piece of data that contributes to the literature.

Among the studies conducted in Turkey, there are also researches addressing to predictors of digit survival. In one of them, 85 replanted/revascularized digits of 60 patients were analyzed by Oruc et al., ${ }^{[3]} \mathrm{a}$ survival rate of $50.5 \%$ was documented, and negative predictors of survival were reported as female sex and crush or avulsion type of injury. The authors reported the survival rates of digits of females and males as $10 \%$ and $90 \%$, respectively, and the statistically significant difference between the sexes was thought to be related to the narrower blood vessels of females. Contrary to the study above and some others ${ }^{[8,9,12,19]}$ and, consistent with further studies, we could not confirm any correlation between sex and the survival rates of replanted digits in this study.

In the study of Dogan et al., ${ }^{[10]} 30$ patients with $35 \mathrm{replanted} /$ revascularized digits were reviewed, an $85.7 \%$ survival rate was reported, and a lower rate of survival was seen for the patients with crush 
injuries. Furthermore, the authors found that the survival rate was lower for patients who underwent a revascularization procedure, although they did not offer any explanation for this finding. In a doctoral thesis, ${ }^{[20]}$ the surgical outcomes of replantation/ revascularization procedures performed under digital blockade or general anesthesia were compared, and a $70.3 \%$ survival rate was reported for 50 patients with 54 amputated digits. The type of anesthesia was not found to be associated with success or failure, and the presence of postoperative arterial or venous insufficiency, and, contrary to our findings, the increased time between the injury and surgery were negative predictors of digit survival.

Similar to our study, Fufa et al. ${ }^{[18]}$ reported that injury to the radial digits $\left(1^{\text {st }}, 2^{\text {nd }}\right.$, and $3^{\text {rd }}$ digits $)$ was a positive predictor of digit survival. Compared to the other digits, the narrower vasculature and weaker perivascular soft tissue support, which may increase the severity of the trauma, may be the reason for the lower survival rate of amputations of the $5^{\text {th }}$ digit in the present series. In addition, Fufa et al. ${ }^{[18]}$ found that the non-dominant hand's digits were more commonly injured in their series, and, contrary to our findings, there was no significant difference regarding the survival rate of non-dominant and dominant hand digits. ${ }^{[18]}$ Although there was no significant difference regarding the distribution of negative and positive predictors between the patients with dominant or non-dominant hand injuries of the present series, the lower survival rate of dominant hand digits can be attributed to the anxiety of the patients following the injury that they would not regain full functional use of their dominant hands and the sympathetic activation and vascular changes caused by this psychosomatic situation. The findings of the study by Tessler et al., ${ }^{[19]}$ partially support our view, which is the dominant hand's digits or the $5^{\text {th }}$ digit were found to be negative predictors, by demonstrating that the patients who underwent dominant hand revision amputation had higher anxiety levels than those who underwent non-dominant hand revision amputation in the long-term. ${ }^{[19]}$

The main limitation of our study is the lack of a sufficient number of cases to ensure a homogeneous distribution of digit amputations which are independent variables between the comparative subgroups. The fact that the sex distribution is not homogeneous among the study groups is an important limitation that negatively affects the variable of sex as a negative predictor of replantation. In addition, another limitation is the inability to determine whether the sociodemographic and cultural differences that affect the physiotherapy after replantation are homogeneously distributed in the study.

In conclusion, salvage of amputated digits is a valuable procedure in suitably selected cases with satisfying survival rates. The predictors of survival identified in the present study can be used as a guide for surgeons and as an aid for the selection of patients. Further multi-center, and long-term prospective studies are needed in the field of digit amputation to better characterize the predictors of survival and functional outcomes.

\section{Declaration of conflicting interests}

The authors declared no conflicts of interest with respect to the authorship and/or publication of this article.

\section{Funding}

The authors received no financial support for the research and/or authorship of this article.

\section{REFERENCES}

1. Yu H, Wei L, Liang B, Hou S, Wang J, Yang Y. Nonsurgical factors of digital replantation and survival rate: A metaanalysis. Indian J Orthop 2015;49:265-71.

2. Hustedt JW, Chung A, Bohl DD, Olmscheid N, Edwards S. Evaluating the effect of comorbidities on the success, risk, and cost of digital replantation. J Hand Surg Am 2016;41:1145-52.e1.

3. Oruç M, Gürsoy K, Özer K, Çolak Ö, Kankaya Y, Sungur $\mathrm{N}$, et al. Eight years of clinical experience with digit replantation: Demographic characteristics and outcomes. Ulus Travma Acil Cerrahi Derg 2017;23:311-6.

4. Shim HS, Kwon BY, Seo BF, Kwon H, Jung SN. A prospective randomised comparison of fixation methods in Tamai's zone I amputation. J Plast Reconstr Aesthet Surg 2018;71:997-1003.

5. Nikolis A, Tahiri Y, St-Supery V, Harris PG, Landes G, Lessard $\mathrm{L}$, et al. Intravenous heparin use in digital replantation and revascularization: The Quebec Provincial Replantation program experience. Microsurgery 2011;31:421-7.

6. Yoshimura M. Indications and limits of digital replantation. JMAJ 2003;46:460-7.

7. Atik OŞ. Is there something new and interesting in my article? Eklem Hastalik Cerrahisi 2019;30:69.

8. Çelikdelen P, Özçelik İB, Mersa B, Purisa H, Sezer İ, Aydın A. Parmak replantasyonlarında rehabilitasyon uygulamalarımız ve fonksiyonel sonuçlarımız. El ve Mikrocerrahi 2012;1:3-6.

9. Shaterian A, Rajaii R, Kanack M, Evans GRD, Leis A. Predictors of digit survival following replantation: Quantitative review and meta-analysis. J Hand Microsurg 2018;10:66-73.

10. Doğan S, Ertem K, Karakaplan M, Sevimli R, Arı B, Yılmaz Ö. Clinical results of minor upper extremity replantation and revascularisation patients in comparison to the literature: A clinical study. J Turgut Ozal Med Cent 2015;22:243-8.

11. Fırat C, Aytekin AH, ErbaturS, Geyik Y, Elmas Ö. Çocuklarda Zon 2 seviyesindeki replantasyon deneyimlerimiz. Dicle Tip Dergisi 2012;39:276-9. 
12. Ozçelik IB, Purisa H, Mersa B, Sezer I, Ertürer E, Ergün O. Başparmak distal uç amputasyonlarinda replantasyon uygulamalarının geç dönem sonuçları. Acta Orthop Traumatol Turc 2008;42:252-7.

13. Gülgönen A, Güdemez E. Başparmak avulsiyon yaralanmalarında replantasyon. Turkiye Klinikleri J Orthop \& Traumatol-Special Topics 2009;2:43-8.

14. Demirtaş Y, Çifci M, Söylemez F, Güneren E, Karacalar A. Çoklu replantasyonlarda başarıyı etkileyen faktörler. Turk J Plast Surg 2008;16:55-6.

15. Waikakul S, Sakkarnkosol S, Vanadurongwan V, Un-nanuntana A. Results of 1018 digital replantations in 552 patients. Injury 2000;31:33-40.

16. DecW. A meta-analysis of success rates for digit replantation. Tech Hand Up Extrem Surg 2006;10:124-9.
17. Mulders MA, Neuhaus V, Becker SJ, Lee SG, Ring DC. Replantation and revascularization vs. amputation in injured digits. Hand (N Y) 2013;8:267-73.

18. Fufa D, Calfee R, Wall L, Zeng W, Goldfarb C. Digit replantation: Experience of two U.S. academic level-I trauma centers. J Bone Joint Surg [Am] 2013;95:2127-34.

19. Tessler O, Bartow MJ, Tremblay-Champagne MP, Lin AM, Landes G, Sebbag S, et al. Long-term health-related quality of life outcomes in digital replantation versus revision amputation. J Reconstr Microsurg 2017;33:446-51.

20. Çinal H. Dijital blok anestezisi ve genel anestezi yöntemleri ile yapılan el parmak replantasyonlarının retrospektif olarak karşılaştırılması. [Uzmanlık Tezi], Ankara: Atatürk Üniversitesi Tıp Fakültesi, Plastik Rekonstrüktif ve Estetik Cerrahi Ana Bilim Dalı; 2014. 